\title{
Measurement of Indoor and Outdoor Background Ionising Radiation Levels of Kwali General Hospital, Abuja
}

\author{
*11JAMES, IU; MOSES, IF; VANDI, JN; IKOH UE \\ Nuclear Technology Centre, Nigeria Atomic Energy Commission, Sheda-Abuja, P.M.B O7, Gwagwalada, Abuja, \\ Email: jamesfam2002@yahoo.com
}

KEYWORDS: Background ionising radiation, Geiger muller counter, radiation monitor, equivalent dose, indoor and outdoor measurement

\begin{abstract}
Measurement of indoor and outdoor background ionising radiation level at Kwali General Hospital, Abuja, Nigeria was carried out using a well calibrated Geiger muller counter; Atomtex AT1117M radiation monitor. The dose equivalent results obtained range from $0.100 \pm 0.001 \mu \mathrm{Sv} / \mathrm{h}$ to $0.124 \pm 0.007 \mu \mathrm{Sv} / \mathrm{h}$ with an average of $0.107 \pm 0.003 \mu \mathrm{Sv} / \mathrm{h}$ for indoor measurement while it ranges from $0.100 \pm 0.001 \mu \mathrm{Sv} / \mathrm{h}$ to $0.122 \pm 0.003 \mu \mathrm{Sv} / \mathrm{h}$ with an average of $0.108 \pm 0.003 \mu \mathrm{Sv} / \mathrm{h}$ for outdoor measurement respectively. The obtained values are below the standard background radiation of $0.133 \mu \mathrm{Sv} / \mathrm{h}$. The study also revealed that the average annual equivalent dose rate is $0.750 \pm 0.020 \mathrm{mSv} / \mathrm{y}$ and $0.189 \pm 0.005 \mathrm{mSv} / \mathrm{y}$ for indoor and outdoor measurements respectively. These results revealed that the dose levels in all of the locations (indoor and outdoor) were below the $1 \mathrm{mSv} / \mathrm{y}$ maximum permissible limit for the public set by International Commission on Radiological Protection (ICRP). Therefore, Kwali General Hospital is radiologically safe @JASEM
\end{abstract}

\section{http://dx.doi.org/10.4314/jasem.v19i1.12}

Introduction

Background radiation consists of three primary types: Primordial, cosmogenic and anthropogenic. Primordial radionuclides are present in the earth's crust and found throughout the environment. Cosmogenic radionuclides are produced when cosmic radiation interacts with elements present in the atmosphere and are deposited through both wet and dry deposition. Anthropogenic sources of radiation result from human activities, but are considered background because their presence is ubiquitous (Okeyode and Oluseye, 2010). Human beings are exposed to background radiation that stems both from natural and man-made sources. In general, approximately $85 \%$ of the annual total radiation dose of any person comes from natural radionuclides of both terrestrial and cosmogenic origin (Belivernis et al, 2010; UNSCEAR, 2000).

Ionizing radiation has been increasingly applied in medicine and is now firmly established as an essential tool for diagnosis and therapy. The overwhelming benefits accruing to patients from properly conducted procedures have fostered the widespread practice of medical radiology, with the result that medical radiation exposures have become an important component of the total radiation exposure of populations. In most developed countries with an advanced health care system, medical exposures are now the most important single source of ionizing radiation (UNSCEAR, 2000).

Radiation from hospitals and medical research institutes has been of great concern because of the known effects of high dosages. Exposure of patients to radiographic examination (computerized tomography, fluoroscopic procedures, dental diagnosis, and routine exposure to $\mathrm{x}$-rays), radioisotope procedures and radiation therapy have contributed to increase in background radiation and radiation levels of patients and many occupational workers (Avwiri, 2011).

Ionizing radiation has the ability to affect the chemical state of a material and so cause changes which are biologically important (Jwanbot et al, 2013). Exposure to ionizing radiation can cause injuries and clinical symptoms; which may include a chromosomal transformation, cancer induction, free radical formation, bone necrosis and radiation catractogenesis (Norman, 1997). The injuries and clinical symptoms could be caused by both chronic and acute dose exposure. Because of the lethal effects of ionizing radiation, the practice has been to monitor 
and assess the levels of exposure and keep one's exposure to ionizing radiation As Low As Reasonably Achievable (ALARA). Studies carried out by Jwanbot et al., (2012) showed that the background ionising radiation of Skane Radiodiagnostic Centre, Jos, plateau state was 2.063 $\mathrm{mSv} / \mathrm{y}$ and $1.848 \mathrm{mSv} / \mathrm{y}$ for indoor and outdoor measurement respectively while for Plateau State Specialist Hospital, the indoor and outdoor results were $2.444 \mathrm{mSv} / \mathrm{y}$ and $2.002 \mathrm{mSv} / \mathrm{y}$ respectively. Okoye and Avwiri (2013) measured the background ionising radiation level at Braithwaite Memorial Specialist Hospital Port Harcourt, Rivers State. Results obtained range from $0.16 \pm 0.01 \mu \mathrm{Sv} / \mathrm{h}$ to $0.14 \pm 0.02 \mu \mathrm{Sv} / \mathrm{h}$ with an average of $0.146 \pm 0.02$ $\mu \mathrm{Sv} / \mathrm{h}$ for indoor measurement within $\mathrm{x}$-ray department, $0.17 \pm 0.02 \mu \mathrm{Sv} / \mathrm{h}$ to $0.1 \pm 0.01 \mu \mathrm{Sv} / \mathrm{h}$ with an average of $0.1413 \pm 0.02 \mu \mathrm{Sv} / \mathrm{h}$ for measurements in departments and locations within the hospital, $0.19 \mu \mathrm{Sv} / \mathrm{h}$ to $0.12 \pm 0.01 \mu \mathrm{Sv} / \mathrm{h}$ with an average of $0.136 \pm 0.02 \mu \mathrm{Sv} / \mathrm{h}$ for indoor measurements in wards within the hospital.

\section{MATERIALS AND METHODS}

An in-situ approach of background radiation measurement was adopted and preferred to enable samples maintain their original environmental characteristics. The indoor and outdoor radiation levels of Eighteen (18) locations in General Hospital Kwali were measured using a radiation monitor, Atomtex AT $1117 \mathrm{M}$ with serial no 14199 . The Atomtex AT $1117 \mathrm{M}$ is a portable combined multifunction radiation monitor with digital readout, designed for measuring X-ray, gamma and neutron radiation ambient dose equivalent, density of alpha and beta radiation flux density from contaminated surfaces, alpha and beta radiation surface activity and neutron flux density. The AT1117M radiation monitor consists of a processing unit and a set of detection units. Radiation monitor operation algorithm provides measurement continuity, calculation moving average values, real time display of detection unit data on integrated display, statistical processing of measurement results, real-time statistical fluctuation estimation and rapid accommodation to changes in radiation level.

The monitor was suspended in air at one meter above the ground level. Readings were obtained between the hours of 1200 and 1600 hours since the exposure rate meter has a maximum response to environmental radiation within these hours. Five readings were
Kwali General Hospital is a 36-bedded general hospital. It started operations in September 2003, and was officially commissioned to a fully fledged General Hospital in April 2005.The hospital serves Kwali Town, Yangoji, Dabi, Bako, Kwaita, Gadabiu, Ashara, Pai, Lambata, Big and Small Sheda, Gwagwalada and Kuje. Kwali General Hospital provides secondary healthcare services in areas of Obstetrics and Gynaecology, general surgery, ultrasound, ECG, and general medical and paediatrics consultation services. Other service include 24 hours automated laboratory services, family planning and immunization. The hospital is located along Gwagwalada-Abuja road on the outskirt of Kwali Town. Other structure within the vicinity of the hospital includes Kwali Area Council Secretariat, Local Education Authority (LEA) Office, and the High Court of Justice Kwali. The hospital has a landmass of about 1,600 sq meters. The present study was conducted to monitor and quantitatively document the background radiation levels within Kwali General Hospital, Abuja, ascertain its radiation burden and provide base-line data for future studies.

taken at each indoor and outdoor location and the mean values were recorded.

UNSCEAR (2000) recommended indoor and outdoor occupancy factors of 0.8 and 0.2 respectively. This occupancy factor (OF) is the proportion of the total time during which an individual is exposed to a radiation field. Eight thousand seven hundred and sixty hours per year $(8760 \mathrm{hr} / \mathrm{yr})$ was used. To convert the equivalent dose rate in $\mu \mathrm{Sv} / \mathrm{h}$ into annual equivalent dose rate in $\mathrm{mSv} / \mathrm{y}$, the equations below were used:

Annual Indoor Equivalent Dose Rate $(\mathrm{mSv} / \mathrm{y})=$ Indoor Equivalent dose rate $(\mu \mathrm{Sv} / \mathrm{h}) \times 8760(\mathrm{~h} / \mathrm{y}) \times$ 0.8 (indoor occupancy factor) $\times 0.001$

Annual Outdoor Equivalent Dose Rate $(\mathrm{mSv} / \mathbf{y})=$ Outdoor Equivalent dose rate $(\mu \mathrm{Sv} / \mathrm{h}) \times 8760(\mathrm{~h} / \mathrm{y}) \times$ 0.2 (Outdoor occupancy factor) $\times 0.001$

\section{RESULTS AND DISCUSSION}

Table 1 shows the mean dose equivalent readings and the annual equivalent dose readings, obtained by using equations (1) and (2) of both indoor and outdoor measurements. Generally, from the result the mean dose equivalent ranged from $0.100 \pm 0.001$ $\mu \mathrm{Sv} / \mathrm{h}$ to $0.124 \pm 0.007 \mu \mathrm{Sv} / \mathrm{h}$ with an average of $0.107 \pm 0.003 \mu \mathrm{Sv} / \mathrm{h}$ for indoor measurement while it ranges from $0.100 \pm 0.001 \mu \mathrm{Sv} / \mathrm{h}$ to $0.122 \pm 0.003$ $\mu \mathrm{Sv} / \mathrm{h}$ with an average of $0.108 \pm 0.003 \mu \mathrm{Sv} / \mathrm{h}$ for outdoor measurement respectively. The mean value 
from locations A7 (Generator house) and A8 (GOPD) shows the highest and lowest equivalent dose rate for indoor measurements respectively while A7 (Generator house) and A11 (Male Ward) shows highest and lowest equivalent dose rate for outdoor measurements respectively. The average values for both indoor and outdoor measurement is below the standard background radiation of $0.133 \mu \mathrm{Sv} / \mathrm{h}$. Location A7 (Generator house) had the highest value for both indoor and outdoor measurement. This result from location A7 (Generator house) is associated with leakages of petroleum products such as oil and diesel which have been associated with radionuclides (Avwiri, et al, 2009). Equivalent dose rate is the measure of the amount of radionuclides absorbed by the human body for a given period. To avoid any somatic, epidemiological and radiological health side effect, ICRP recommended and consequently set the maximum permissible limit for non-radionuclide industrial worker and the public as $1 \mathrm{mSvy}^{-1}$. Fig. 1 shows the comparison of different locations Indoor mean annual dose rate equivalent with standard annual equivalent dose rate (ICRP maximum permissible limit). Fig. 2 shows the comparison of different locations Outdoor mean annual dose rate equivalent with standard annual equivalent dose rate (ICRP maximum permissible limit). The results revealed that the dose levels in all of the locations (indoor and outdoor) were below the maximum permissible limit for the public. Generally, the results are lower compared with previous work at radio diagnostic centre (Jwanbot et al, 2012), plateau state specialist hospital (Jwanbot et al, 2012) and Braithwaite Memorial Specialist Hospital Port Harcourt, Rivers State (Okoye and Avwiri, 2013). Also the results are lower when compared with department of radiology and nuclear medicine, New Mexico Veterans Administration Healthcare System, United State of America (Mettler et al, 2008) and some hospitals in Kathmandu city, Nepal (Karan et al, 2007) where radiation measurement was carried out. Furthermore, the radiological burden of the Kwali General Hospital is within the permissible value of ICRP and lower than that of a nuclear establishment (Oyeyinka et al, 2012) located within the same area council.

Table 1: Table of Readings

\begin{tabular}{clcccc}
\hline $\begin{array}{c}\text { Cod } \\
\text { e }\end{array}$ & \multicolumn{1}{c}{$\begin{array}{c}\text { Location } \\
\text { Name }\end{array}$} & $\begin{array}{c}\text { Mean Dose } \\
\text { Equivalent } \\
(\mu \mathrm{Sv} / \mathrm{h}) \\
\text { Indoor }\end{array}$ & $\begin{array}{c}\text { Mean Dose } \\
\text { Equivalent } \\
(\mu \mathrm{Sv} / \mathrm{h}) \\
\text { Outdoor }\end{array}$ & $\begin{array}{c}\text { Annual Dose } \\
\text { Equivalent } \\
(\mathrm{mSv} / \mathrm{h}) \\
\text { Indoor }\end{array}$ & $\begin{array}{c}\text { Annual Dose Equivalent } \\
(\mathrm{mSv} / \mathrm{h}) \\
\text { Outdoor }\end{array}$ \\
\hline A1 & Admin Building & $0.106 \pm 0.001$ & $0.107 \pm 0.002$ & $0.740 \pm 0.009$ & $0.187 \pm 0.004$ \\
$\mathrm{~A} 2$ & Antenatal & $0.105 \pm 0.001$ & $0.105 \pm 0.003$ & $0.734 \pm 0.010$ & $0.183 \pm 0.005$ \\
$\mathrm{~A} 3$ & Canteen & $0.104 \pm 0.006$ & $0.114 \pm 0.005$ & $0.727 \pm 0.043$ & $0.200 \pm 0.008$ \\
A4 & Casualty Unit & $0.102 \pm 0.001$ & $0.102 \pm 0.001$ & $0.712 \pm 0.008$ & $0.179 \pm 0.002$ \\
A5 & Eye Centre/Clinic & $0.108 \pm 0.002$ & $0.101 \pm 0.002$ & $0.757 \pm 0.011$ & $0.177 \pm 0.004$ \\
A6 & Gatehouse & $0.109 \pm 0.001$ & $0.111 \pm 0.001$ & $0.767 \pm 0.008$ & $0.195 \pm 0.002$ \\
A7 & Generator House & $0.124 \pm 0.007$ & $0.122 \pm 0.003$ & $0.869 \pm 0.052$ & $0.213 \pm 0.005$ \\
A8 & GOPD & $0.100 \pm 0.001$ & $0.102 \pm 0.001$ & $0.701 \pm 0.005$ & $0.178 \pm 0.001$ \\
A9 & Gynaecology & $0.108 \pm 0.001$ & $0.106 \pm 0.002$ & $0.755 \pm 0.006$ & $0.186 \pm 0.003$ \\
A10 & Laboratory & $0.102 \pm 0.001$ & $0.104 \pm 0.001$ & $0.716 \pm 0.006$ & $0.183 \pm 0.002$ \\
A11 & Male Ward & $0.104 \pm 0.001$ & $0.100 \pm 0.001$ & $0.727 \pm 0.008$ & $0.176 \pm 0.00$ \\
A12 & Maternity & $0.108 \pm 0.002$ & $0.107 \pm 0.002$ & $0.757 \pm 0.011$ & $0.187 \pm 0.003$ \\
A13 & Mortuary & $0.117 \pm 0.010$ & $0.116 \pm 0.010$ & $0.820 \pm 0.072$ & $0.203 \pm 0.018$ \\
A14 & New Building & $0.105 \pm 0.002$ & $0.106 \pm 0.001$ & $0.736 \pm 0.014$ & $0.186 \pm 0.002$ \\
A15 & Operating Theatre & $0.102 \pm 0.005$ & $0.107 \pm 0.005$ & $0.713 \pm 0.033$ & $0.188 \pm 0.009$ \\
A16 & Pediatrics & $0.107 \pm 0.004$ & $0.109 \pm 0.004$ & $0.753 \pm 0.027$ & $0.191 \pm 0.007$ \\
A17 & Postnatal & $0.105 \pm 0.003$ & $0.107 \pm 0.001$ & $0.737 \pm 0.021$ & $0.187 \pm 0.001$ \\
A18 & Staff Quarters & $0.110 \pm 0.003$ & $0.114 \pm 0.005$ & $0.772 \pm 0.019$ & $0.200 \pm 0.009$ \\
& AVERAGE & $0.107 \pm 0.003$ & $0.108 \pm 0.003$ & $0.750 \pm 0.020$ & $0.189 \pm 0.005$ \\
\hline
\end{tabular}




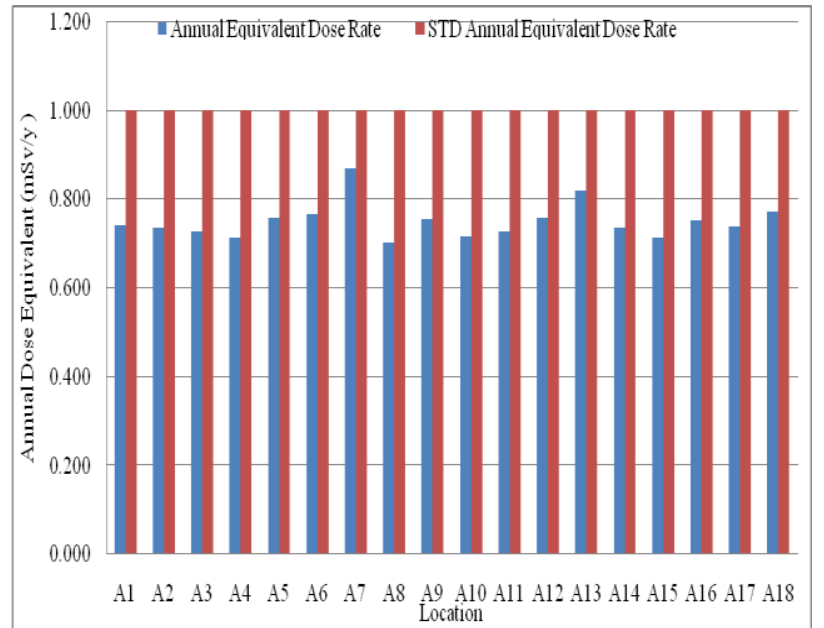

Fig 1: Comparison of different locations Indoor mean annual dose rate equivalent with standard annual equivalent dose rate

Conclusion: The indoor and outdoor measurements of background ionising radiation level at Kwali General Hospital, Abuja, Nigeria was carried out using a well calibrated radiation monitor. An in-situ measurement approach was adopted using Atomtex AT1117M. The measurements were carried out in 18 locations within the hospital. The study showed that the mean equivalent dose rate and the annual equivalent dose rate levels are within the standard permissible limits set by the International Commission on Radiological Protection (ICRP). Hence the hospital is radiologically safe.

Acknowledgements: We wish to express our gratitude to the Director, Gamma Irradiation Facility, Nigeria Atomic Energy Commission and the Medical Director, Kwali General Hospital for their kind assistance and support in one way or the other in the course of this research.

\section{REFERENCES}

Okeyode I. C and Oluseye A. M (2010). Studies of the Terrestrial outdoor Gamma Dose Rate Levels in Ogun-Osun River Basins Development Authority Headquarters, Abeokuta, Nigeria. Physics International 1 (1): $1-8$.

Belivermis, M; Kılıç, N; Çotuk, Y; Topcuoğlu, S. (2010). The effects of physicochemical

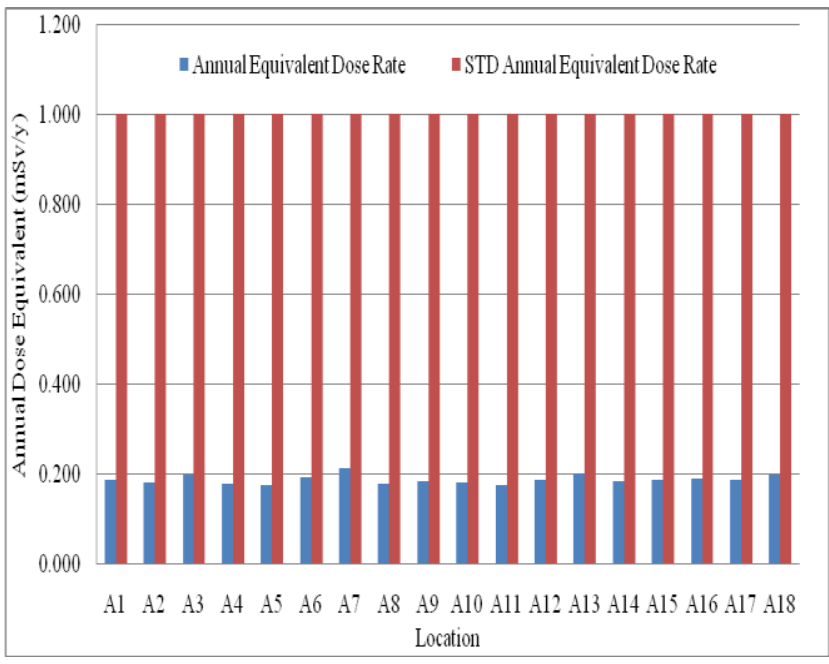

Fig 2: Comparison of different locations Outdoor mean annual dose rate equivalent with standard annual equivalent dose rate

properties on gamma emitting natural radionuclide levels in the soil profile of Istanbul. Environ Monit Assess. 163 (1-4): 1526.

UNSCEAR (2000). United Nation Scientific Committee on the Effects of Atomic Radiation. Sources and effect of Ionizing radiation. Report to the general assembly with scientific annexes. United Nations; New York.

Avwiri G O (2011). Radiation - the Good, the Bad and the Ugly in our Environment. An Inaugural Lecture 79th Series University of Port Harcourt.

Jwanbot, D. I; Izam, M. M; Nyam, G. G; Dakon, R. J. (2013). Environmental Ionizing Radiation Distribution Profile in Jos and Environs. Journal of Environment and Earth Science 3 (3): 87-94.

Norman, A and Kagan, A. R (1997).

"Point/Counterpoint: Radiation Doses in Radiation Therapy are not safe". Med. Phys. 24(11): 1710-1713

Jwanbot, D. I; Izam, M. M; Nyam G. G; Agada, I. S (2012). Evaluation of Indoor background ionising radiation profile in some hospitals in Jos Plateau state Nigeria. Journal of Natural Sciences Research 2 (7): 35-40. 
Okoye, P. C. and Avwiri, G. O (2013).

Evaluation of background ionising radiation levels of Braithwaite Memorial Specialist Hospital Port Harcourt, Rivers State. Am. J. Sci. Ind. Res. 4(4): 359-365.

Avwiri G O ,Chad-Umoren Y E, Enyinna P I,

Agbalagba E O (2009). Occupational radiation profile of oil and gas facilities during production and off production periods in Ughelli, Nigeria. FACTA UNIVERSITATIS Series: Working and Living Environmental Protection 6 (1): 11-19.

Mettler Jr, F. A; Walter, H; Terry, T. Y;

Mahadevappa, M (2008). Effective Doses in Radiology and Diagnostic Nuclear Medicine. A Catalog. Radiology 248(1):254-263
Karan, G; Dhiraj, G; Krishna M. V (2007).

Radiation Measurement at X-Ray centres of a few Hospitals in Kathmandu City, Nepal. Kathmandu University Journal of Science, Engineering and Technology 1 (4):1-4.

Oyeyinka O. D; James I. U; Akueche E. C; Shonowo O. A; Adesanmi C. A. (2012). Estimation of Radiation Dose Rate Levels around a Nuclear Establishment in Abuja, North Central, Nigeria. Science and Technology 2(6): 163-167. 